\title{
Developing The Radius Turner as The Radius Turning Tool
}

\author{
Nurdjito, Asnawi, Paryanto, Surono \\ Faculty of Engineering \\ Universitas Negeri Yogyakarta \\ nurdjito@uny.ac.id., asnawi@uny.ac.id.,paryanto@uny.ac.id,suronogk@uny.ac.id
}

\begin{abstract}
The study was conducted in order to determine: (1) the feasibility of radius turner as a radius turning assistance tool; and (2) the achievement of radius turning competency displayed by the students after they had operated the radius turner. The design that the researchers applied in conducting the study was the Research and Development (R\&D) with the ADDIE Model. The data for the study were gathered from the second semester students who attended the B1, B2 and D1 Lathe Machinery Class. Within the data collection, the researchers applied the observation, the questionnaires and the documentation. Then, for the data analysis the researchers implemented the descriptive quantitative technique. The results of the study have been as follows: (1) the radius turner that have been developed successfully is fit for its use as the radius turning tool in the radius profile of the lathe; and (2) the students' radius turning competency achievement after they have operated the radius turner have been $81.00 \%$ in achieving the maximum score.
\end{abstract}

\section{Keywords — radius turner, assisting tool, radius turning}

\section{INTRODUCTION}

The Lathe Machinery Class is a compulsory practicum class that the Diploma 3 or Strata 1 students should attend with an objective to provide the competencies in the lathe machinery domain. Therefore, in order to master the competencies maximally the students should be supported and one of the supports that might be provided is the sufficient practicum tool. However, up to date the practicum tool still becomes one of the main problems in conducting the machinery practicum learning. For the Lathe Machinery Class, ideally 1 student operates 1 lathe machine and yet there are only 10 lathe machines in the ready-to-operate condition whereas the number of students in each practicum class is around 15-20 people; as a result, the students should take turn in operating the machine. In addition, in order to master several competencies within the class, there should be medium/assisting tool variation in manufacturing multiple profile variations contained in the practicum job. Unfortunately, the number of medium/assisting tool is so limited that in the same time the students should take turn in operating the medium/assisting tool.

One of the competencies that are contained in the Lathe Machine is the radius turning. The manufacture of radius profile in the turning process might be conducted in two manners namely by using the radius turning chisel or by using the radius turner. Up to date, the manufacture of radius profile has been conducted by using the radius turning chisel that has been molded manually by means of grinding machine. In the practice, the students only rely on the radius turning chisel that has been available among the technicians; they are lazy to grind the chisel independently. The manufacture of radius profile by means of radius turning chisel still has weaknesses namely that the radius dimension is very difficult to be achieved accurately. So far, the shape of the radius might be achieved but the dimension of the radius has not been accurate after the measurement has been conducted.

In order to achieve the radius dimension in accordance with the job that has been assigned, the process of radius lathe manufacture might use the radius turning medium/assisting tool. However, the problem is that such medium or assisting tool have not been possessed by the Department of Engineering Education. On the other hand, such medium or assisting tool have not been available in the market as well but there are some shops or garages that are willing to manufacture such medium or tools with a quite high price namely IDR $5,000,000.00 /$ unit. In addition, the tool provision encounters certain procedures that should be gone through and the procedures take a long time. These problems should be solved immediately. Therefore, through the peer discussion and sharing within the study the researchers would like to focus on developing the radius turning medium/assisting tool that we would like to call as the radius turner independently. Hopefully, the radius turner provision might be realized soon.

For the initial stage, the radius turner is designed and is adjusted to the Ciamik lathe machine available in the machinery garage. The radius turner is designed to have easiness in the adjustment and the tool might be adjusted to $90^{\circ}$ radius manufacture in maximum. The radius turner is equipped with the tool holder for the insert lathe chisel so that when the chisel gets worn out it might be easily replaced. With the radius turner, the researchers would like to expect that the radius turner might optimize the students' competency achievement especially for the radius turning process.

Based on the background of the study, the problems that will be the focus of solution in the study are: (1) How is the radius turner feasibility as the radius turning medium/assisting tool; and (2) How is the students' competency achievement after they have operated the radius turner? In accordance with 
the problems, the objectives of the study then will be: (1) to identify the radius turner feasibility as the radius turning medium/assisting tool; and (2) to identify the students' radius turning competency achievement after they have operated the radius turner.

The process of product development in general refers to the steps or the activities in which an institution affords to arrange, to design and to commercialize a product (Ulrich \& Eppinger, 2001: 14). The process of product development in general consists of several stages or also known as phases. According to Ulrich \& Eppinger (2001: 15-17) the process of product development in general consists of six phases as follows:

1. Planning: the planning phase is frequently known as the "zero" phase because the activities in this phase are the preliminary process of the product development or are the ones of approving a project and the process of releasing the actual product development. The output of the process is the mission statement of the project that serves as the necessary input for starting the concept development and that also serves as the guideline for the developer team.

2. Concept development: in this phase the needs of target market are identified, the product alternatives are displayed and are evaluated and one of the concepts will be selected for further development and experiment. The concept referred in this phase is the elaboration on the form, the function and the display of a product and usually the concept is accompanied by a set of specifications, analyses, competing products and economical consideration for the project.

3. System level design: the phase includes the product architecture definition and the product elaboration into the subsystems and the components. The output in this phase usually includes the layout of the product form and the functional specification from each final manufacture.

4. Detail design: the phase includes the complete specification in terms of form, materials and tolerance from all of the unit components in the product and the identification toward the all of the standard components that have been provided by the suppliers. The process plan is stated and the tool is design for each component that will be manufactured within the production system. The output in this phase is the note of control for the product, the picture in the form of computer file for each product component and its production tools, the specification of the components that have been purchase and the plan for fabrication process and product manufacture.

5. Testing and experiment: this phase involves construction and evaluation from multiple product versions of the initial production. The initial prototype (alpha) usually is manufactured by using the components with the material types and forms in the actual production; however, the initial prototype does not demand the fabrication process that is similar to the actual fabrication process. The alpha prototype is tested in order to determine whether the product will be working in accordance to the plan and whether the product will satisfy the needs of the main customers. The subsequent prototype (beta) is usually manufactured with the necessary components in the production but is not assembled by means of final assembly process as in the actual production process. The beta prototype is evaluated internally and is tested by the customers through the direct operation. The target of the prototype beta is usually to answer the questions regarding the performance and the reliability in order to identify the needs of technical changes for the final product.

6. Initial production: in this phase the product is manufactured $b$ using the actual production system. The objective of the phase is to train the labors in solving the problems that might occur in the actual process production. The generated product during the initial production sometimes is adjusted to the customers' desires and is evaluated carefully in order to identify the weaknesses that appear. The changes from the initial production into the actual production should go phase by phase. In several points of the transition period, the product is released and is prepared for distribution.

Another development procedure is the ADDIE Model that consists of Analysis, Design, Development or Production, Implementation or Delivery and Evaluations. According to the steps of product development, such research and development model is more rational and complete. Therefore, the model might be implemented for multiple form of product development such as models, learning strategies, learning methods, learning medium and teaching materials.

The ADDIE Model has been developed by Dick \& Carry (1996). Each development stage/procedure in the ADDIE Model will be explained as follows:

1. Analysis: in this stage, the main activity is to analyze the necessity of developing a product, a new learning model/method and the feasibility or the requirements of product development of the new learning model/method. In addition, in the stage a researcher also conducts a needs analysis toward the product development or the learning model/method development that will be performed.

2. Design: after the analysis has been conducted, the next stage is designing the product or the learning model $/$ method that will be developed. The design stage is the guidelines for the process of product development so that the stage should be conducted systematically and specifically. The design of the product and the learning model/method is still conceptual and will be the basis of the subsequent development process.

3. Development: the development stage in the ADDIE model contains the activities of realizing the product design or the product manufacture design. In this stage, the conceptual framework (in the design stage) will be realized into the product that will be ready for implementation.

4. Implementation: in this stage a researcher implements the product design and the method that has been developed in the actual situation namely in the learning stage. The product that has been manufactured/been developed will be put into the actual experiment and then the researcher 
performs the preliminary evaluation in order to provide feedback toward the functions of the product that has been developed.

5. Evaluation: evaluation is conducted in order to identify the function and the performance of a product and a learning model/method. The results of the evaluation will be used for providing feedback to the users in relation to the revisions that should be pursued. The revisions are made in accordance with the results of the evaluation or the needs that have not been able to be met by the new product or model/method.

Medium are the messenger from the sender to the retriever (Arief S. Sadiman et al., 1986: 6). Several definitions have been provided by the experts who study the learning medium or the instructional medium. Briggs (1970) quoted by Arief S. Sadiman et al. (1986: 6) defines that "medium refer to all physical tools that might display messages and stimulate the students to learn." On the other hand, Gagne (1970) quoted by Arief S. Sadiman et al. (1986: 6) explains that, "medium refer to the multiple components within the students' environment that might stimulate them to learn."

Learning is an activity that involves an individual to attain knowledge, skills and positive values by benefitting multiple sources to learn (Rudi \& Cepi, 2008: 1). On the contrary, Degeng (1993) quoted by Hamzah, Nina and Satria (2010: 4) explains that "learning is an effort of educating the students."

In addition to the definitions of medium and learning that have been elaborated previously, the experts also provide the definition of learning medium. Schramm quoted by Rudi \& Cepi (2008: 6) explains that the learning medium is "a message-carrier technology that might be benefitted for the learning needs." Then, Briggs (1977) quoted in Rudi \& Cepi (2008: 6) states that learning medium are "the physical facilities for delivering the learning contents/materials such as books, films, videos, slides and alike."

From multiple opinions above, the researchers would like to draw a conclusion that:

1. Learning medium is the message container.

2. The materials that will be delivered are the learning messages.

3. The objectives that will be achieved are the learning process.

Radius turner is an assisting tool or equipment in the lathe machine that might be used for manufacturing the radius profile in the turning process. Within the use, the assisting tool is positioned in the tool post component on the lathe machine. By using the assisting tool, the students might gain several advantages in the process of manufacturing the radius profile by operating the lathe machine namely:

1. The radius turner might be adjusted to the various radius profile dimension until $90^{\circ}$ in maximum, both for the concave and the convex radius.

2. The chisel that might be operated is the insert flat chisel.

3. The resulted radius dimension will be more précised.
The radius turner design and the detail components that will be developed are as follows:

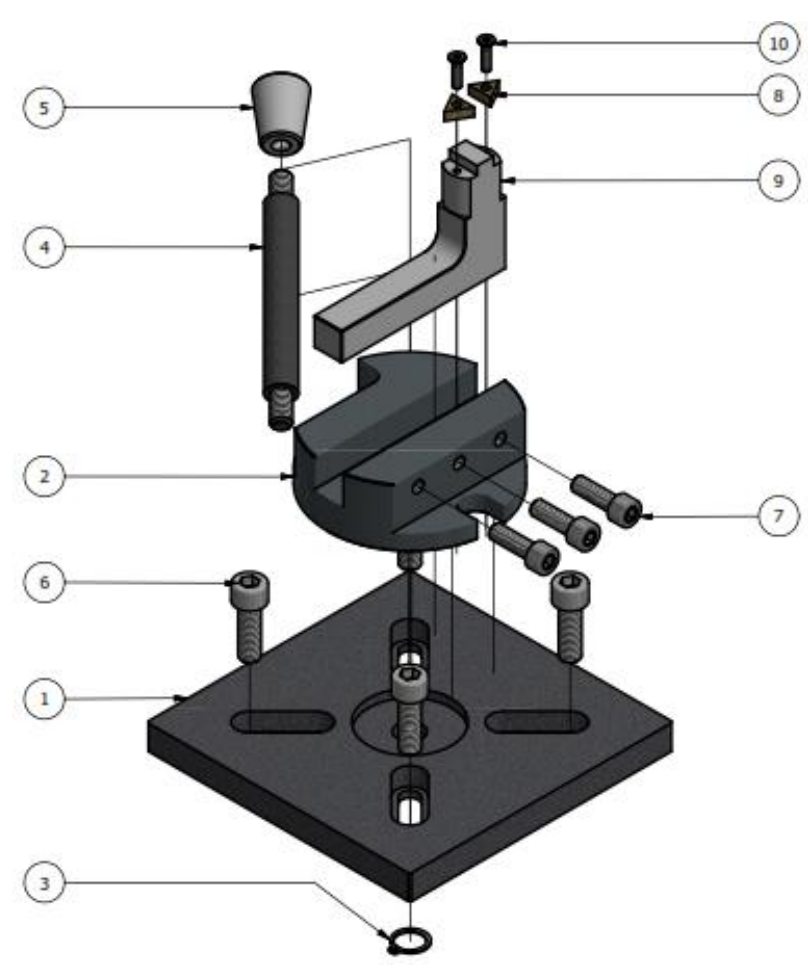

Fig. 1. Radius Turner
Notes:
1. Grounding
2. Tool Post
3. Ring
4. Handle A
5. Handle B
6. Grounding Fastening Bolt
7. Tool Holder Fastening Bolt
8. Tool (Insert)
9. Tool Holder
10. Tool Fastening Bolt

\section{METHOD}

Based on the objectives of the study, the design that the researchers implemented was the Research and Development (R\&D) with the ADDIE Model (Dick \& Carey, 2010). The ADDIE Model had been one of the research and development models that consisted of the following stages: (1) Analysis; (2) Design; (3) Development; (4) Implementation; and (5) Evaluation.

The data sources/subjects in the study were the second semester students who attended the B1, B2 and D1 Lathe Machinery Class. For the data gathering, the researchers conducted the observation, distributed the questionnaires and performed the documentation. The data that had been attained then would be analyzed in the descriptive quantitative manner. 


\section{RESULTS AND DISCUSSIONS}

The study was conducted by following the procedures/stages of development in the ADDIE Model. The results that had been attained from each stage in the study were as follows:

1. Analysis

In this stage the researchers performed the needs analysis toward the radius turner that would be developed. The results of the activities in the stage were as follows:

a. The materials that should be applied were the MS steel adjusted to the available budget.

b. The turning capacity or the radius shape should be $180^{\circ}$ in maximum.

c. The radius turner should be manufactured by adjusting it to the Ciamik machine size and dimension.

d. The radius turner should be installed onto and should be detached from the Ciamik lathe machine.

e. The radius turner should have ease of operation.

f. The construction of the radius turner should not be complicated but should be rigid.

2. Design

The researchers created the design in the form of radius turner drawings in details and in adjustment to the Ciamik-brand lathe machine available in the practicum garage. The radius turner drawings might be viewed in Appendix 5.

3. Development

The researchers developed the radius turner in accordance to the Design stage. In the study, the researchers had manufactured 2 radius turner units. The photo of the two units would be attached in the paper.

4. Implementation

Within the Implementation stage, the radius turner was operated in the practicum class of Lathe Machinery especially as the assisting tool in the radius profile manufacture. The total number of university students who had been involved into the tool operation was 16 people. The process of tool implementation was conducted to the three classes that attended the Lathe Machinery Class. However, since the practicum class consisted of 9 practicum jobs the specific focus of the radius turner operation was on the job of manufacturing the tool holder. Since the number of the available lathe machines had been limited, the researchers divided the jobs to the students. As a result, in average until the sixth meeting there were five students who had accomplished the tool holder manufacture by means of radius turner operation within the radius dimension manufacture.

From the job object (tool holder) that had been submitted, the results of assessment toward the radius profile from the overall 16 students might be viewed in Table I.
TABLE I.

The Assessment of Students' Practicum Results

\begin{tabular}{|r|r|r|}
\hline \multicolumn{1}{|c|}{ No } & \multicolumn{1}{|c|}{ Respondent } & \multicolumn{1}{c|}{ Score } \\
\hline 1 & 1 & 5.00 \\
\hline 2 & 2 & 6.00 \\
\hline 3 & 3 & 6.00 \\
\hline 4 & 4 & 6.00 \\
\hline 5 & 5 & 6.00 \\
\hline 6 & 6 & 6.00 \\
\hline 7 & 7 & 6.00 \\
\hline 8 & 8 & 6.00 \\
\hline 9 & 9 & 6.00 \\
\hline 10 & 10 & 6.00 \\
\hline 11 & 11 & 5.00 \\
\hline 12 & 12 & 6.00 \\
\hline 13 & 13 & 5.00 \\
\hline 14 & 14 & 6.00 \\
\hline 15 & 15 & 6.00 \\
\hline 16 & 16 & 6.00 \\
\hline & Mean & $\mathbf{5 . 9 0}$ \\
\hline
\end{tabular}

The maximum score in the assessment toward the radius profile had been 6 ; therefore, based on the above data, $81.00 \%$ of the respondents attained the maximum score.

5. Evaluation

Based on the results of the observation and of the students' response questionnaires, the researchers evaluated the radius turner in order to improve it in the subsequent stage. The feedback or the responses from the students might be viewed in Table II.

The data then would be analyzed and be interpreted by means of the following formula:

$\begin{array}{lll}\mathrm{Mi}+1,5 \mathrm{SD} & <\mathrm{X} \leq \mathrm{Mi}+3 \mathrm{SD} & \text { Very Feasible } \\ \mathrm{Mi} & <\mathrm{X} \leq \mathrm{Mi}+1.50 \mathrm{SD} & \text { Feasible } \\ \mathrm{Mi}-1,5 \mathrm{SD} & <\mathrm{X} \leq \mathrm{Mi} & \text { Less Feasible } \\ \mathrm{Mi}-3 \mathrm{SD} & \leq \mathrm{X} \leq \mathrm{Mi}-1.50 \mathrm{SD} & \text { Not Feasible }\end{array}$

After the data had been calculated, the researchers found that:

\begin{tabular}{|c|c|c|c|}
\hline 3.25 & $<\mathrm{X} \leq$ & 4 & Very Feasible \\
\hline 2.50 & $<\mathrm{X} \leq$ & 3.25 & Feasible \\
\hline 7 & $<\mathrm{X} \leq$ & 2.50 & Less Feasible \\
\hline $0 \Omega$ & $\leq X$ & 1.75 & Not Feasible \\
\hline
\end{tabular}

Eventually, the data that had been attained from the students' responses would be interpreted in Table III. 
TABLE II. STUDENTS' RESPONSES TOWARD THE USE OF RADIUS TURNER

\begin{tabular}{|c|c|c|c|c|c|c|c|c|c|c|c|c|c|c|c|c|c|c|}
\hline \multirow{2}{*}{ No. } & \multirow{2}{*}{ Aspect under Observation } & \multicolumn{16}{|c|}{ Respondents } & \multirow{2}{*}{ Mean } \\
\hline & & 1 & 2 & 3 & 4 & 5 & 6 & 7 & 8 & 9 & 10 & 11 & 12 & 13 & 14 & 15 & 16 & \\
\hline 1 & The radius turner manual is easy to understand. & 4 & 3 & 4 & 3 & 3 & 4 & 3 & 3 & 3 & 3 & 4 & 3 & 4 & 2 & 2 & 4 & 3.25 \\
\hline 2 & The radius turner operation is easy to conduct. & 4 & 4 & 4 & 3 & 3 & 4 & 4 & 3 & 4 & 4 & 3 & 4 & 4 & 3 & 3 & 4 & 3.63 \\
\hline 3 & The radius turner might function well. & 3 & 2 & 3 & 2 & 3 & 2 & 3 & 2 & 3 & 3 & 3 & 4 & 3 & 3 & 3 & 2 & 2.75 \\
\hline 4 & $\begin{array}{l}\text { The radius turner is able to sustain the vibration } \\
\text { during the turning process. }\end{array}$ & 2 & 2 & 2 & 3 & 3 & 2 & 3 & 3 & 3 & 3 & 3 & 2 & 4 & 3 & 2 & 1 & 2.56 \\
\hline 5 & The radius turner has good strength. & 2 & 3 & 2 & 3 & 3 & 3 & 2 & 3 & 3 & 3 & 3 & 2 & 3 & 3 & 3 & 1 & 2.63 \\
\hline 6 & $\begin{array}{l}\text { The results of radius turning by means of radius } \\
\text { turner operation are good. }\end{array}$ & 3 & 3 & 3 & 2 & 3 & 2 & 3 & 3 & 3 & 4 & 3 & 4 & 3 & 3 & 3 & 2 & 2.94 \\
\hline 7 & In general, the radius turner product has been good. & 3 & 3 & 3 & 3 & 2 & 3 & 3 & 3 & 2 & 4 & 3 & 3 & 4 & 3 & 3 & 2 & 2.94 \\
\hline
\end{tabular}

TABLE III. INTERPRETATION OF THE STUDENTS' RESPONSE DATA

\begin{tabular}{|l|l|l|l|}
\hline No. & \multicolumn{1}{|c|}{ Aspect under Observation } & Mean & Interpretation \\
\hline 1 & $\begin{array}{l}\text { The radius turner manual is easy to } \\
\text { understand. }\end{array}$ & 3.25 & Very Feasible \\
\hline 2 & $\begin{array}{l}\text { The radius turner operation is easy to } \\
\text { conduct. }\end{array}$ & 3.63 & Very Feasible \\
\hline 3 & The radius turner might function well. & 2.75 & Feasible \\
\hline 4 & $\begin{array}{l}\text { The radius turner is able to sustain the } \\
\text { vibration during the turning process. }\end{array}$ & 2.56 & Feasible \\
\hline 5 & $\begin{array}{l}\text { The radius turner has good strength. } \\
\text { The results of radius turning by means of } \\
\text { radius turner operation are good. }\end{array}$ & 2.94 & Feasible \\
\hline 7 & $\begin{array}{l}\text { In general, the radius turner product has } \\
\text { been good. }\end{array}$ & 2.94 & Feasible \\
\hline
\end{tabular}

Based on the results of the implementation, within the process of manufacturing the radius profile by operating the radius turner the researchers found that the radius turner still had some weaknesses namely: (1) the radius turner did not have the scale of radius angle dimension and as a consequence there had not been any guidelines for determining the size of the radius that would be manufactured; (2) the horizontal arm in the chisel holder part was too long and as a consequence the adjustment to attain the radius angle had been very limited because there had been a great risk that the turning chuck might be hit during the adjustment process; and (3) the etch in the handle part was not perfect and as a consequence the installment of the radius turner might not be neat and the radius turner would be very shaky.

In order to overcome those weaknesses, the researchers improved the tool by drawing the scale line of the radius angle dimension. The line was drawn in the chisel holder part and the tool post part. Then, the length of the horizontal arm in the chisel holder part was shortened for about $20 \mathrm{~mm}$ so that the researchers might adjust the radius angle at any degree (both for the convex and the concave one) without having to be afraid of hitting the turning chuck. The next improvement would be conducted toward the handle part by repeating the etch-drawing processin order that that the newer etch would be smoother and more perfect. In addition, on the tool post especially in the handle installation part the researchers repeated the etchdrawing process by using the tap so that the etch line became more perfect. After installing the radius turner, the handle became more rigid and was not shaky because the tie had been more perfect.

Based on the data from the students' responses toward the radius turner feasibility, from the mean score within the seven aspects that had been proposed, five aspects belonged to the "Feasible" category and two aspects belonged to the "Very Feasible" category. In overall, the researchers might conclude that the radius turner that had been developed would be feasible for its implementation as the medium or the assisting tool within the radius profile manufacture.

On the contrary, based on the data from the assessment toward the job object, especially toward the radius profile in which the maximum score of the assessment had been equal to 6 , the university students who attained the score 6 were 13 people and the remaining 3 students attained the score 5 . Thereby, in terms of percentage, there were $81.00 \%$ of the students who attained the maximum score in the assessment. The percentage proved that the use of radius turner in the learning process, especially in the radius profile manufacture, had been able to maximize the achievement of radius turning competencies.

\section{CONCLUSIONS}

Based on the results that have been attained in the study, the researchers would like to draw the following conclusions: 
1. The radius turner that has been successfully developed might be feasible for the implementation as the medium or the assisting tool in the radius profile manufacture.

2. The achievement of the students' radius turning competencies has been $81.00 \%$ of the maximum score after the implementation of the radius turner operation.

\section{REFERENCES}

[1] Arief S.Sadiman,dkk. (1986). Media Pendidikan: Pengertian, Pengembangan, dan Pemanfaatannya. Jakarta: CV.Rajawali.

[2] Dick \&Carey. (2010). ADDIE Model. diakses pada tanggal 1 Maret 2010 dari:http://www.learning-theories.com/addie-model.html

[3] Hamzah,B.U.,Nina, L.,\&Satria,K.(2010).DesainPembelajaran.Bandung: MQSPublishing.

[4] Rudi,S.,\&Cepi,R.(2008).MediaPembelajaran.Bandung:JurusanKurtekpe ndFIPUPI.

[5] Ulrich, K.T., Eppinger, S.D. (2001). Product Design and Development Mc Graw-Hill 